\title{
KONSEP LANDASAN TEORI DAN RANCANGAN SILABUS PEMBELAJARAN MAHARAH ISTIMA DI PERGURUAN TINGGI
}

\author{
Cahya Edi Setyawan \\ Sekolah Tinggi Agama Islam Masjid Syuhada Yogyakarta \\ E-mail: cahya.edi24@gmail.com
}

\begin{abstract}
Abstrak
Dalam pembelajaran kemahiran mendengar dan berbicara bahasa arab ada beberaapa tingkatan yang harus dipahami oleh para guru, dosen, dan praktisi akademik. tingkatan pembelajaran itu didasarkan oleh standar kemampuan belajar yang dimulai dari awal. tingkatan tersebut diklasifikasikan dalam bentuk tingkatan dasar, tingkatan menengah, dan tingkatan atas. dalam tingkatan-tingkatan tersebut terdapat standar kemampuan yang harus dipelajari. Standar tersebut akan menjadi standar kompetensi lulusan yang wajib atau lazim dikuasai oleh pembelajar bahasa. terdapat pola-pola kemampuan diantaranya dalam pembelajaran istima, yaitu 1) latihan pengenalan atau identifikasi, 2) latihan mendengarkan atau mengidentifikasi, 3) latihan mendengar atau memahami.
\end{abstract}

Kata kunci : Pembelajaran Istima, Pembelajaran Kalam, Standar Kemampuan.

\section{Abstract}

Learning the ability to hear and speak Arabic there are several levels that must be understood by teachers, lecturers, and academic practitioners. the level of learning is based on the standard of learning ability that starts from the beginning. these levels are classified in terms of basic, intermediate, and upper level levels. in these levels there is a standard of ability to be learned. These standards will become the competency standards of graduates that are required or commonly controlled by language learners. there are patterns of abilities among them in learning istima, namely 1) recognition or identification practice, 2) listening or identifying exercises, 3) listening or understanding exercises.

Keywords: Istima Learning, Kalam Learning, Standard Of Ability 
Cahya Edi Setyawan: Konsep Landasan Teori dsn Rancangan Silabus Pembelajaran Maharah Istima' di Perguruan Tinggi

\section{A. PENDAHUluan}

Dalam Pembelajaran bahasa Arab ada empat kemahiran yang perlu dipelajari oleh peserta didik, empat kemahiran (Maharah) tersebut adalah maharah istima', maharah kalam, maharah qiraah, dan maharah kitabah. Kenapa maharah istima' dan kalam didahulukan daripada maharah qiraah dan kitabah, karena kemahiran ini merupakan hal pertama yang dialami oleh manusia dalam pembelajaran bahasa. Dalam proses pemerolehan bahasa (Iktisabul Lughah) dimulai dengan mendengarkan, hal hal yang terdengar disimpan dalam memori bahasa dalam otak manusia kemudian setelah itu dituturkan kembali oleh manusia. Setelah manusia mampu mendengar dan bertutur dia memulai untuk membaca dan menulis.

Kemahiran mendengar merupakan kemahiran pertama yang akan dialami oleh manusia. Kemudian yang terpenting setelah mendengar maka manusia akan mengungkapan apa yang sudah didengar melalui kemahiran berbicara. Dalam konteks pembelajaran bahasa Arab, mahārat istima termasuk keterampilan pokok yang harus dikuasai siswa dan merupakan langkah awal dalam penguasaan kompetensi bahasa. Vallet dalam Fathi Ali Yunus mengatakan bahwa sejak lebih dari 22 tahunan yang lalu, diantara faktor yang mendorong siswa untuk mempelajari bahasa Asing adalah agar bisa berkomunikasi dengan penutur bahasa yang dipelajarinya, termasuk komunikasi mendengar dan berbicara. ${ }^{186}$ Senada dengan pendapat Vallet.

186 Fathi Ali dan Muhammad Yunus Abd al-Rauf. Al-Marji' Fi Ta'lim alLughah al-Arabiyyah Li al-Ajanib Min al-Nadzariyyah Ila al- Tathbiq.alQahirah: Maktabah Wahbah. 2003. hal. 168 
Cahya Edi Setyawan: Konsep Landasan Teori dsn Rancangan Silabus Pembelajaran Maharah Istima' di Perguruan Tinggi

Menyimak atau istima' merupakan keterampilan dalam berbahasa arab yang memungkinkan seseorang untuk memahami bahasa arab yang digunakan secara lisan, sehingga terhindar dari kesalahpahaman dalam berkomunikasai yang dapat menyebabkan berbagai hambatan dalam pelaksanaan tugas dan kegiatan sehari-hari. Dengan memiliki penguasaan keterampilan menyimak yang mamadai, duharapkan siswa terbiasa dengan bunyi-bunyi bahasa arab yang pada akhirnya memungkinkannya untuk melafalkan bunyi-bunyi tersebut dengan benar.

Sebagai salah satu dari empat kemampuan berbahasa, mendengar merupakan keterampilan yang memungkinkan seorang pemakai bahasa untuk memahami bahasa yang digunakan secara lisan. Karena banyaknya komunikasi seharihari yang dilakukan secara lisan, kemampuan ini amat penting dimiliki oleh setiap pemakai bahasa. Tanpa kemampuan mendengar yang baik, akan terjadi banyak kesalah-pahaman dalam komunikasi antara sesama pemakai bahasa yang dapat menyebabkan berbagai hambatan dalam melaksanakan tugas dan kehidupan sehari-hari. Oleh karena itu kemampuan mendengar merupakan bagian yang tak boleh diabaikan dalam pengajaran bahasa terutama bila tujuan penyelenggaraannya adalah penguasaan kemampuan berbahasa. 187 Dari hal-hal diatas akan dibahas tentang konsep pembelajaran istima dan silabusnya sebagai berikut. ${ }^{188}$

188 M. Soenardi Djiwandono, Tes Bahasa Dalam Pengajaran (Bandung: Penerbit ITB, 1996), hal. 54-55 
Cahya Edi Setyawan: Konsep Landasan Teori dsn Rancangan Silabus Pembelajaran Maharah Istima' di Perguruan Tinggi

\section{B. PEMBAHASAN}

1. Pemahaman Dasar Pembelajaran Istima (Kemahiran Mendengar)

a. Pengertian Pembelajaran Istima'

Istima' secara etimologi berasal dari bahasa Arab Istama'a-Yastami'u yang berarti mendengakan atau menyimak. Istima' secara istilah adalah sarana yang pertama yang digunakan manusia untuk berhubungan dengan sesama manusia dalam tahapan-tahapan tetentu, melalui menyimak kita mengenal mufrodat (kata), bentuk-bentuk jumlah (kalimat) dan tarakib (Susunan beberapa kata). 189 Proses menyimak memusatkan perhatian kepada objek yang disimak dalam rangka mencapai maksud-maksud tertentu. Misalnya, untuk tujuan belajar, mengapresiasi sebuah karya, mendapatkan informasi khusus, memecahkan masalah, atau untuk memahami aspek-aspek sebuah bahasa. 190

b. Tujuan Pembelajaran Istima'

Secara umum tujuan pembelajaran istima' adalah agar siswa mampu mengenali bunyi ujaran, mengidentifikasi kata, frasa, dan kalimat, memperoleh informasi, menginterpretasi, menangkap makna, menyimpulkan makna, merespon, mengapresiasi, mengkritisi, dan menilai. Dilihat dari tujuan diatas, maka tujuan pembelajaran istima' pada tingkat lanjut adalah : 1) mampu mengikuti dan beradaptasi dengan tempo pembicaraan, 2) mampu memvisualisasikan

189 MyNiceSpace.com, makruf Imam, Bahan Ajar : strategi Pembelajaran Aktif. Diakses pada: 4 november 2017, pukul: 20.25 WIB

190 Gulo, W. Strategi Belajar - Mengajar, Jakarta : Grasindo, 2002 
Cahya Edi Setyawan: Konsep Landasan Teori dsn Rancangan Silabus Pembelajaran Maharah Istima' di Perguruan Tinggi

peristiwa yang didengar dari berbagai ungkapan bahasa Arab, 3) mampu memahami makna ujaran sesuai dengan konteks budaya Arab, 4) mampu menangkap gagasan utama dari paparan yang didengar, 5) mampu membedakan antara gagasan utama dengan gagasan pendukung , 6) mampu membedakan antara fakta dan pendapat perorangan yang difahami dari konteks paparan lisan, 7) mampu menangkap makna kontekstual dari penggunaan kata yang digunakan oleh pembicara, 8) mampu memberikan respon yang tepat terhadap suatu ungkapan yang didengar, 9) mampu menyimpulkan isi kandungan pembicaraan, 10) mampu memberikan penilaian terhadap ungkapan yang didengar.

c. Prinsip-Prinsip Pembelajaran Istima'

Dalam pembelajaran istima' perlu diperhatikan hal-hal berikut: 191 1. pendengar menerima informasi melalui rangkaian bunyi bahasa dengan susunan nada dan tekanan penempatan persendian (juncture), 2. Dalam tutur pembicaraan atau dalam teks yang dilisankan, biasanya terdapat gagasan pokok dan gagasan penunjang, 3. dalam memilih teks lisan hendaknya guru memperhatikan hal- hal ini yaitu usia dan minat siswa, kosakata yang dimiliki siswa, tingkat kematangan dan kecepatan siswa dalam mengikuti teks lisan, 4. kecepatan yang wajar. Untuk tahap-tahap permulaan tidak ada salahnya kalau ucapan diperlambat sedikit, 5. penggunaan alat peraga banyak

191 Mustofa, Syaiful. Strategi Pembelajaran Bahasa Arab Inovatif. hal. 126-127 
Cahya Edi Setyawan: Konsep Landasan Teori dsn Rancangan Silabus Pembelajaran Maharah Istima' di Perguruan Tinggi

sekali manfaatnya dan dapat membantu mempercepat pengertian, 5. untuk tingkat lanjut, situasi perlu dibuat mendekati situasi sehari-hari. Gangguan-gangguan seperti background musik atau suara orang lain yang sedang bercakap-cakap, perlu dengan sengaja dimasukkan dalam rekaman agar menambah tingkat kesulitan untuk menyimak, 6. guru sebaiknya menuliskan kata-kata kunci tertentu sebelum pelajaran dimulai dan menjelaskan maknanya, 7. guru hendaknya menyampaikan kepada siswa tentang petunjuk yang jelas, 8. untuk mengetahui sejauh mana pemahaman siswa terhadap apa yang didengarkannya, maka setiap materi yang disajikan hendaknya dilengkapi dengan pertanyaan-pertanyaan.

d. Prosedur Pembelajaran Istima'

Ada beberapa petunjuk umum yang harus diperhatikan oleh seoarang guru dalam pembelajaran istima', yaitu sebagai berikut: 192 1) hendaknya guru menjadi contoh yang baik sebagai media istima'nya, 2) hendaknya guru membuat rencana pelajaran istima' dengan baik dan terstruktur, 3) Variatif dalam komunikasi, tidak hanya terbatas guru dan siswa, bisa jadi antar siswa, 4) kejelasan ketrampilan istima' yang hendak dicapai, 5) memperhatikan kondisi siswa, 6) ucapannya jelas dan fasih, 7) guru hendaknya memperhatikan irama dan intonasi, 8) mengulang-ulang (tidak membatasi pengulangan), 9) pembelajaran yang

192 www.slideshare.net. Prosedur dan Tekhnik Pengajaran Aswat Dan Maharah Al-Istima'. Diakses pada: 5 desember 2017 pukul: 15.30 WIB 
Cahya Edi Setyawan: Konsep Landasan Teori dsn Rancangan Silabus Pembelajaran Maharah Istima' di Perguruan Tinggi

menyenangkan, 10) guru berusaha mengkondisikan siswa mengikuti pelajaran istima'.

e. Model Pembelajaran Istima'

Dalam pembelajaran menyimak terdapat berbagai macam model strategi yang dapat digunakan oleh seorang pengajar, yaitu:

1) Model saling kerjasama. Perserta didik saling berbagi hasil belajar dari materi yang sama dengan cara berbeda, dengan membandingkan catatan hasil belajar.

2) Menyimpulkan. Strategi ini dapat menguji kemampuan menyimak peserta didik terhadap isi cerita. Jawaban peserta didik terhadap pertanyaan seperti:

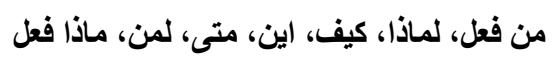

Yang kemudian disintetiskan kedalam satu kalimat singkat, padat dan jelas sehingga dapat menumbuhkan proses berfikir kreatif, kritis terhadap topik yang diberikan.

3) Saling bergantian. Strategi ini dapat mengiringi siswa untuk tetap konsentrasi dan terfokus pada materi yang sedang disampaikan.

4) Menyimak dengan lagu.

5) Model informasi.

6) Model problematika.

f. Tahapan-tahapan dalam pembelajaran Istima'

Adapun tahapnan-tahapan yang dapat dilakukan dalam latihan istima' adalah sebagai berikut:193

193 Ahmad Fuad Efendy, Metode Pengajaran Bahasa Arab. hal. 129- 
Cahya Edi Setyawan: Konsep Landasan Teori dsn Rancangan Silabus Pembelajaran Maharah Istima' di Perguruan Tinggi

\section{1) Latihan pengenalan (identifikasi)}

Guru harus memberikan perhatian khusus kepada bunyi-bunyi hurufdan kata-kata Arab dengan bantuan media baik guru sendiri maupun rekaman dengan tape recorder atau di laboratorium bahasa. Latihan mengenal (identifikasi) ini bisa berupa latihan dengar untuk membedakan (discrimination exercises) dengan teknik mengontraskan pasangan-pasangan ucapan yang hampir sama. Misalnya: Guru mengucapkan atau memutarkan rekaman, pelajar diminta menebak, apakah yang didengarnya itu bunyi A, B, C atau D. Contoh:
a)

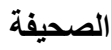
b)

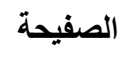
c) الصفحة
d)

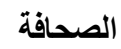

Memperdengarkan satu set yang terdiri dari 3-4 kata sebagian mengandung bunyi bahasa yang ingin dilatihkan. Murid diminta mengidentifikasi dengan menyebut nomor kata-kata yang mengandung bunyi tersebut. Misalnya, untuk mengidentifikasi bunyi (ق) guru memperdengarkan:
a)
مقعد
b)
مقبول
c)

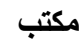

Murid merespons dengan menyebutkan angka: satu, dua tiga. 
Cahya Edi Setyawan: Konsep Landasan Teori dsn Rancangan Silabus Pembelajaran Maharah Istima' di Perguruan Tinggi

1) Latihan mendengarkan dan menirukan.

Latihan menirukan ini difokuskan pada bunyi-bunyi bahasa yang asing bagi siswa, juga pada pengucapan vokal panjang dan pendek, bertasydid dan tidak bertasydid, yang tidak dikenal dalam bahasa Arab. Beberapa contoh:

a) Latihan pengucapan bunyi ( $b$ )

Guru mengucapkan murid menirukan:

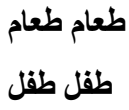

b) Latihan pengucapan vokal bertasydid.

Guru-Siswa :

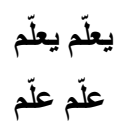

Latihan-latihan mendengarkan dan menirukan

(listen and repeat / الاستماع والترديد ) ini akan lebih efisien dan efektif kalau dilakukan dilaboratorium bahasa, sebab berbagai teknik bisa dipraktekkan.

2) Latihan mendengarkan dan memahami

Tahap selanjutnya, setelah siswa mengenal bunyibunyi bahasa dan dapat mengucapkannya. Untuk pemahaman ini dapat dilakukan dengan berbagai macam teknik, antara lain:

a) latihan melihat dan mendengar (انظر واسمع)

Guru memperdengarkan materi yang sudah direkam, dan pada waktu yang sama memperlihatkan rangkaian gambar yang mencerminkan arti dan isi materi yang didengar oleh siswa tadi. Gambar-gambar tersebut bisa berupa film-strip, slide, gambar dinding dan sebagainya. 
Cahya Edi Setyawan: Konsep Landasan Teori dsn Rancangan Silabus Pembelajaran Maharah Istima' di Perguruan Tinggi

b) Latihan membaca dan mendengar (اقرأ واسمع)

Guru memperdengarkan materi bacaan yang sudah direkam dan siswa membaca teks (dalam hati) mengikuti materi yang diperdengarkan. Pada tingkat permulaan, perbendaharaan kata-kata yang dimiliki siswa masih terbatas. Oleh karena itu, harus dipilihkan bahan yang pendek-pendek, mungkin berupa percakapan sehari-hari atau ungkapan-ungkapan sederhana yang tidak terlalu kompleks.

c) Latihan mendengarkan dan memeragakan ( قرأ ومثّل )

Dalam latihan ini, siswa diminta melakukan gerakan atau tindakan non verbal sebagai jawaban terhadap stimulus yang diperdengarkan oleh guru. Kegiatan ini tidak terbatas pada ungkapan sehari-hari digunakan oleh guru dalam kelas seperti:

$$
\text { اقرا - أققل الكتاب - اجلس - اكتبوا - امسح السبورة - افتح الشباك }
$$

Ketiga jenis latihan yang disebutkan diatas, adalah latihan permulaan bagi jenis latihan berikutnya, yakni latihan pemahaman ( فهم المسموع ) yang lebih luas.

g. Stategi Pembalajaran Istima

Beberapa strategi yang dapat dikembangkan dalam pembelajaran istima' ini adalah:194

1) Strategi 1 (True or False)

Strategi ini bertujuan untuk melatih kemampuan mendengarkan bacaan dan memahami isi bacaannya secara global. Dalam strategi ini yang dibutuhkan adalah rekaman bacaan dan potongan-

194 www.slideshare.net. Prosedur dan Tekhnik Pengajaran Aswat Dan Maharah Al-Istima'. Diakses pada: 19 Maret 2018 pukul: 13.00 WIB 
Cahya Edi Setyawan: Konsep Landasan Teori dsn Rancangan Silabus Pembelajaran Maharah Istima' di Perguruan Tinggi

potongan teks yang terkait dengan isi bacaan tersebut untuk dibagikan kepada siswa.

2) Strategi 2 (Merekam)

Strategi ini lebih menekankan pada aspek kemampuan memahami isi bacaan dan menjawab pertanyaan-pertanyaan yang mengiringi dalam setiap bacaan tersebut.

3) Strategi 3 (Mengungkap kembali/Presentasi)

Strategi ini tidak hanya menitik beratkan pada aspek kemampuan memahami isi bacaan, tetapi juga kemampuan untuk mengungkapkan kembali apa yang sudah didengarnya dengan bahasa sendiri.

h. Kelebihan dan kekurangan pembelajaran istima

Pembelajaran menyimak (Istima') ini memiliki beberapa kelebihan, yaitu sebagai berikut:

1) Melatih kecermatan dalam mendengarkan/memperhatikan;

Keterampilan menyimak dapat melatih sejauh mana siswa dapat mencermati atau mendengarkan apaapa yang diperdengarkan kepada mereka. Meliputi suara (Ashwat), kalimat-kalimat, isi dan lainnya.

2) Lebih kuat diingat;

Menyimak dalam hal ini berkaitan dengan mendegar adalah keterampilan yang menggunakan panca indera pendengaran atau telinga. Sudah kita ketahui bahwasanya hal yang paling dulu difahami oleh manusia dari bahasa adalah melalui mendengar. Hal ini menjadi salah satu faktor utama dalam mengingat ujaran bahasa yang telah ia dengar dengan kuat. 
Cahya Edi Setyawan: Konsep Landasan Teori dsn Rancangan Silabus Pembelajaran Maharah Istima' di Perguruan Tinggi

3) Cepat mengerti;

Melalui keterampilan menyimak ini, siswa akan lebih dapat dimengerti atau memahami isi/kandungan apa-apa yang diperdengarkan kepadanya. Karena mendengar adalah kegiatan yang sangat praktis, berbeda dengan misalnya membaca yang cenderung lebih menguras kejelian indera penglihatan (mata) dan pikiran (otak) yang berfungsi dalam memahami kata demi kata atau paragraf demi paragraf suatu bacaan.

Pembelajaran menyimak (Ta'lim al-Istima') tak selamnya memiliki kelebihan saja, pembelajaran Menyimak juga memiliki beragam kekurangan atau kelemahan, diantaranya sebagai berikut:

1) Para pelajar cenderung untuk memberi respon secara serentak dan secara mekanistis seperti membeo (babga'iy), mereka sering tidak mengetahui atau tidak memikirkan makna ujaran yang diucapkan penutur bahasa tersebut.

2) Makna kalimat yang diajarkan biasanya terlepas dari konteks, sehingga pelajar hanya memahami satu makna, padahal suatu kalimat atau ungkapan bisa mempunyai beberapa makna tergantung konteksnya.

3) Sebetulnya para pelajar juga tidak berperan dikelas (keaktifan semu), karena mereka hanya memberi respon pada rangsangan guru.

4) Karena kesalahan dianggap sebagai "dosa”, maka pelajar tidak dianjurkan berinteraksi secara lisan atau tulisan sebelum menguasai benar pola-pola kalimat yang cukup banyak. Akibatnya, pelajar takut menggunakan bahasa. 
Cahya Edi Setyawan: Konsep Landasan Teori dsn Rancangan Silabus Pembelajaran Maharah Istima' di Perguruan Tinggi

5) Latihan-latihan pola bersikap manipulatif, tidak kontekstual dan tidak realistis. Pelajar mengalami kesulitan ketika menerapkannya dalam konteks komunikatif yang sebenarnya. 195

2. Contoh SAP Pembelajaran Maharah istima di Perguruan Tinggi Agama Islam Masjid Syuhada Yogyakarta (STAIMS)

\begin{tabular}{|ll|}
\hline Nama Mata Kuliah & $:$ Maharah Istima' \\
Tipe Mata Kuliah & $:$ Wajib \\
Bobot Kredit & $: 2 \mathrm{sks}$ \\
Semester & $:$ III \\
Jurusan & $:$ PBA \\
Dosen & $:$ Mega Pragmaningtyas , M. Pd.I \\
HP & $:$ O85434526125 \\
Email & $:$ mega_pragma@gmail.com \\
\hline
\end{tabular}

I. Standar Kompetensi: setelah mengambil mata kuliah ini diharapkan mahasiswa mampu mamiliki kemampuan mendengar dan memahami ungkapan bahasa Arab

II. Kompetensi dasar: diharapkan mahasiswa mampu mengidentifiksi maksud dari sebuah ungkapan bahasa Arab yang didengar dan mampu menjawab sal-soal istima'

195 Fachrurrozi, Aziz. Pembelajaran Bahasa Asing Metode Tradisional dan Kontemporer. 2010. Jakarta: Bania Publishing, hal. 81 
Cahya Edi Setyawan: Konsep Landasan Teori dsn Rancangan Silabus Pembelajaran Maharah Istima' di Perguruan Tinggi

III. Jadwal Perkuliahan

\begin{tabular}{|c|c|c|c|}
\hline No & Pertemuan & Tema & Subyek \\
\hline 1 & I & $\begin{array}{c}\text { Pengantar Kuliah: kontrak } \\
\text { belajar }\end{array}$ & Dosen \\
\hline 2 & II & $\begin{array}{l}\text { Pengertian istima', Tujuan } \\
\text { pembelajaran istima', dn } \\
\text { macam-macam } \\
\text { pembelajaran istima' }\end{array}$ & $\begin{array}{l}\text { Dosen dan } \\
\text { mahasiswa }\end{array}$ \\
\hline 3 & III & $\begin{array}{l}\text { Mendengarakan huruf- } \\
\text { huruf Arab, dan kosakata }\end{array}$ & $\begin{array}{l}\text { Dosen dan } \\
\text { mahasiswa }\end{array}$ \\
\hline 4 & IV & $\begin{array}{c}\text { Mendengarkan hiwar: } \\
\text { Asshaqqah }\end{array}$ & $\begin{array}{l}\text { Dosen dan } \\
\text { mahasiswa }\end{array}$ \\
\hline 5 & V & $\begin{array}{c}\text { Mendengarkan hiwar: } \\
\text { Abdullah wa ahmad } \\
\text { shadiqani }\end{array}$ & $\begin{array}{l}\text { Dosen dan } \\
\text { mahasiswa }\end{array}$ \\
\hline 6 & VI & UTS & $\begin{array}{l}\text { Dosen dan } \\
\text { mahasiswa }\end{array}$ \\
\hline 7 & VII & $\begin{array}{l}\text { Mendengarkan hiwar: } \\
\text { asbabu dha'fil muslimin }\end{array}$ & $\begin{array}{l}\text { Dosen dan } \\
\text { mahasiswa }\end{array}$ \\
\hline 8 & VIII & $\begin{array}{l}\text { Mendengarkan faqrah: } \\
\text { yastaiqidu umar min } \\
\text { naumihi }\end{array}$ & $\begin{array}{l}\text { Dosen dan } \\
\text { mahasiswa }\end{array}$ \\
\hline 9 & IX & $\begin{array}{c}\text { Mendengarkan faqrah: } \\
\text { Abdullah thayyar }\end{array}$ & $\begin{array}{l}\text { Dosen dan } \\
\text { mahasiswa }\end{array}$ \\
\hline 10 & $\mathrm{X}$ & $\begin{array}{l}\text { Mendengarkan faqrah: } \\
\text { qadhau ayyamil 'uthlah }\end{array}$ & $\begin{array}{l}\text { Dosen dan } \\
\text { mahasiswa }\end{array}$ \\
\hline 11 & XI & $\begin{array}{l}\text { Mendengarkan qisshah: } \\
\text { assyabakah addauliyah }\end{array}$ & $\begin{array}{l}\text { Dosen dan } \\
\text { mahasiswa }\end{array}$ \\
\hline
\end{tabular}


Cahya Edi Setyawan: Konsep Landasan Teori dsn Rancangan Silabus Pembelajaran Maharah Istima' di Perguruan Tinggi

\begin{tabular}{|c|c|c|c|}
\hline 12 & XII & $\begin{array}{c}\text { Mendengarkan akhbar } \\
\text { majallat alislamiyah : } \\
\text { almuslimuna yusa'iduna }\end{array}$ & $\begin{array}{c}\text { Dosen dan } \\
\text { mahasiswa }\end{array}$ \\
\hline 13 & XIII & $\begin{array}{c}\text { Mendengarkan khitabah: } \\
\text { samailu rasul SAW }\end{array}$ & Dosen dan \\
& mahasiswa \\
\hline 14 & XIV & UAS (Praktek) & Dosen dan \\
& & & mahasiswa \\
\hline
\end{tabular}

IV. Contoh materi

$$
\begin{aligned}
& \text { ضع علامة الصواب أمام الجملة التي ستسمعها في كل مجموعة }
\end{aligned}
$$

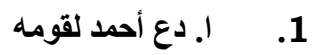

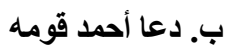

$$
\begin{aligned}
& \text { ج. دعا أحمد لقومه } \\
& \text { 2. . وضع الخطاب في صندوق البريد } \\
& \text { ب. ضع الخطاب في صندوق البريد } \\
& \text { ج. وضعت خطابا في صندوق البريد } \\
& \text { 3. تحركت القطارات من هنا } \\
& \text { ب. تحركت القطار من هنا } \\
& \text { ج. تحرك القطار من هنا }
\end{aligned}
$$

V. Pendekatan Pembelajaran : Drill dan Praktikum 
Cahya Edi Setyawan: Konsep Landasan Teori dsn Rancangan Silabus Pembelajaran Maharah Istima' di Perguruan Tinggi

VI. Aspek Penilaian

\begin{tabular}{|l|l|l|}
\hline No & Komponen Minimal & Bobot \\
\hline 1. & Tugas, diskusi, dan sikap & $30 \%$ \\
\hline 2. & Presensi kehadiran & $10 \%$ \\
\hline 4. & UTS & $30 \%$ \\
\hline 5. & UAS & $30 \%$ \\
\hline Total & $100 \%$ \\
\hline
\end{tabular}

VII. Buku Referensi

1. Al'arabiyah baina yadaika

2. Al'arabiyah linnasyiin

3. Almaharat alasasiyah fillughah al'arabiyah

\section{PENUTUP}

Kesimpulan yang dapat ditarik dari artikel ini adalah:

1. Dalam pembelajaran Istima melibatkan kemampuan pendengaran yang baik, disamping itu membutuhkan media yang baik pula. Media bisa berupa native speaker, guru sendiri. Media bisa juga menggunakan kaset dan diputarkan baik dikelas maupun laboratorium bahasa. Tujuan pembelajarannya menekankan kepada identifikasi bunyi huruf, kata, kalimta, pola ungkapan, dan identifikasi cerita maupun percapakapan panjang.

2. Silabus dalam pembelajaran istima dan kalam dibuat sedemikian rupa guna mempermudah dalam pembelajaran. Agar pembelajaran terstruktur dan terencana dengan baik. Agar pelaksanaan pembelajaran sesuai dengan tujuan yang telah dirumuskan. 
Cahya Edi Setyawan: Konsep Landasan Teori dsn Rancangan Silabus Pembelajaran Maharah Istima' di Perguruan Tinggi 
Cahya Edi Setyawan: Konsep Landasan Teori dsn Rancangan Silabus Pembelajaran Maharah Istima' di Perguruan Tinggi

\section{DAFTAR PUSTAKA}

Ali Fathi dan al-Rauf, M. Abdul, 2003. Al-Marji' Fi Ta'lim al-Lughah al-Arabiyyah Li al-Ajanib Min al-Nadzariyyah Ila alTathbiq.al-Qahirah: Maktabah Wahbah.

Fuad A, Ilyan Makmun. 1992. Al-Maharat al-Lughawiyah: Mahiyatuha wa Thara'iq Tadrisiha. Riyadh: Dar al-Muslim Li al-Nasyr wa al- Tauziee.

Fachrurrozi, Aziz, 2010. Mahyudin Erta Teknik Pembelajaran Bahasa Arab. Tangerang.

Gulo, W. 2002. Strategi Belajar-Mengajar, Jakarta : Grasindo.

Al-Naqah, Mahmud K, 1985, Ta'lim al-Lughah al-Arabiyyah Li alNathiqin Bi Lughat Ukhra: Ususuh, Mahakhiluh, Thuruq Tadrisih. Makkah al-Mukarramah: Jamiecat Um al-Qura.

Hamid, Abdul M, 2008, Pembelajaran Bahasa Arab_Pendekatan, Metode, Materi, Strategi, dan Media. Malang: UIN Malang Press

Makruf, Imam, Bahan Ajar : strategi Pembelajaran Aktif. Diakses pada: 4 november 2017, pukul: 20.25 WIB

Fachrurrozi, Aziz, Mahyuddin E, 2010, Teknik Pembelajaran Bahasa Arab. Tangerang.

Soenardi M. Djiwandono, 1996, Tes Bahasa Dalam Pengajaran Bandung: Penerbit ITB. 
Cahya Edi Setyawan: Konsep Landasan Teori dsn Rancangan Silabus Pembelajaran Maharah Istima' di Perguruan Tinggi 